\title{
Introducing compassion into the education of health care professionals; can Schwartz Rounds help?
}

\author{
R. Barker ${ }^{1 *}$, J. Cornwell ${ }^{2}$ and F. Gishen ${ }^{3}$
}

\begin{abstract}
Whilst health care professionals embark on their careers with high ideals these can be eroded by the pressures and stress of the system. This paper explores the problems, which may lead both students and professionals, working in health care, to feel isolated and stressed. It considers the value of Schwartz Rounds as an initiative that can be used to enhance student well-being and ultimately enable students to treat each other, colleagues and patients with more compassion.

Case description: Qualitative and quantitative data from Schwartz Rounds conducted with medical students at University College London Medical School is drawn on to inform the discussion.

Discussion: Potential mechanisms at play in the Rounds are explored. Further research is needed to look at the cost benefits of Rounds in relation to possible benefits including reduced student attrition. Logistical challenges of running Rounds within and across different disciplines need further investigation.

Conclusion: Early feedback suggests that the Rounds are well received by the students and a number of benefits reported relating to the normalising of emotions and creating channels for more open, transparent modes of communication.
\end{abstract}

Keywords: Education, Medical Student, Teaching, Undergraduate, Curriculum, Schwartz Centre Rounds, Resilience, Compassion, Burnout, Stress, Professionalism

\section{Overview}

Behavioural ideals and professional standards determined for those entering the health care professions (doctors, nurses and allied health professionals) are set high. The notion of professionalism encompasses a broad range of behaviours including; integrity, compassion, altruism, continuous improvement, excellence and good team working [1]. Yet it seems that it is the more technical aspects of this ideal 'package' of behaviours, which are prioritised in curriculum planning [2]. The teaching of clinical facts may appear more straightforward to pass on and test, than traits such as empathy and compassion. This paper explores how Schwartz Rounds may be incorporated into the standard curriculum of health care students to help students to engage in more compassionate, open patterns of communication and care - both with colleagues and

\footnotetext{
* Correspondence: rhiannonbarker@pointofcarefoundation.org.uk ${ }^{1}$ Head of Business Development, Point of Care Foundation, 99 Gray's Inn Road, London W1X 8TY, UK

Full list of author information is available at the end of the article
}

patients. Data from a pilot project [3] at University College London Medical School (UCLMS) where Schwartz Rounds are now being run with years 5 and 6 medical students will be drawn on.

\section{Main text \\ Background}

Schwartz Rounds (Rounds) are an innovation that have been shown to reduce stress, and build engagement and cohesion in multi-disciplinary teams, with the potential to improve the ability of health care staff to show empathy to others (both staff and patients).

High levels of interest have been shown in introducing the Rounds into the context of professional health care education, targeting Rounds at students in medicine, nursing, midwifery, psychology and other allied health professionals. Although the evidence for the benefits of Rounds largely stems from data on staff working in health care organisations, we anticipate that professionals in training are as likely to benefit as staff in post. 
The central hypothesis behind this work is that the sooner reflective, multi-professional support and communication are introduced to professionals in training, the greater the likelihood of enduring benefits.

Early data from piloting Rounds in University College of London Medical School provide evidence that the students value Rounds as a mechanism for reducing stress and learning to share concerns and vulnerabilities in a safe controlled environment. The latest GMC guidance 'Promoting excellence: standards for medical education and training [4] concludes that more could be done to prepare students, to build their resilience and to make sure they are effectively supervised and supported when they begin as an F1 doctor. We suggest that Rounds may be an effective tool to help build student resilience, foster more open communication and perhaps help mitigate the rise in student attrition rates. Ultimately it may be that attending Rounds will impact on the clinical practice of participants; research in the states by Lown and Manning found that Rounds enhanced participants' reported 'likelihood of attending to psychosocial and emotional aspects of care, significantly decreased perceived stress levels, improved the ability to cope with psychosocial demands of care and enhanced their beliefs about the importance of empathy' [5].

Originating from the USA Schwartz Rounds were created as part of the legacy of Ken Schwartz, a health attorney who was diagnosed with lung cancer in 1994 [6]. He found that what mattered to him most as a patient were the simple acts of kindness from his caregivers, which he said made "the unbearable bearable." The underlying premise for Rounds is that the compassion shown by staff can make all the difference to a patient's experience of care, but that in order to provide compassionate care staff must, in turn, feel supported in their work.

Schwartz Rounds offer attendees a regularly scheduled time and place in which they are encouraged to openly and honestly discuss social and emotional issues that arise in caring for patients. They are a forum in which health staff from all backgrounds come together to talk about the (non-clinical) emotional and social challenges in the work of caring for patients. The focus of Rounds is on the human dimension of medicine. The theory of change, articulating how and why the Rounds may work and considering what needs to be in place in order for the Rounds to be most impactful, is complex and will be influenced by context; a large piece of NIHR longitudinal research is currently underway and is expected to report on some of these questions in more detail [7].

Psychological literature notes the value both of telling stories as a form of authentication [8] and of being listened to. Rounds offer participants the opportunity both to share experiences and listen to others, chiming with
Carl Rogers' [9] assertion that listening with empathy has the power to aid growth and healing. Whilst the Rounds are more of a group or community activity, rather than an attempt to enact a traditional one to one therapeutic relationship, the experience and benefits of, listening and being listened to, evoke a powerful response. Sharing experiences can normalise feelings such as anger, fear, inadequacy that may otherwise be viewed as abhorrent, shaming or unusual; needing to remain hidden and concealed.

Psychologists have observed that experiences of death and disease can, particularly in western cultures, invoke a primitive fear. The more serious the illness the stronger are the fears and taboos, and one immediate strategy that staff may employ is to distance themselves [10]. Menzies-Lyth [11] has described how people withdraw, perhaps for their own emotional protection, and hide behind an array of organizational mechanisms that offer protection (be this uniforms, procedures, targets, or language). Referring, for example, to a patient by bed number or condition, may help staff cope more easily when things go wrong ('could you attend to the stroke patient in bed 6?'). This natural avoidance, or self-protection, gets in the way of compassion and good communication and highlights the need to provide staff with time and space to reflect on their reaction to their often stressful work environment. Witnessing human tragedy on a daily basis is harrowing and organizational support is needed to help avoid the cumulative buildup of toxic emotion leading, all too often, to burnout and disillusionment [12].

In NHS organisations, the Rounds normally take place once a month, for an hour at a time, and usually at lunch-time with lunch provided. The first 1015 min is taken up with the team that looked after a patient telling the patient's story or exploring a theme. The following $45 \mathrm{~min}$ is opened up for discussion, guided by a facilitator, exploring issues raised by the story. The central involvement of a Clinical Lead (normally a senior doctor or clinician) is considered an important ingredient to the success of Rounds, encouraging the attendance of other clinicians from across the organisation. At UCLMS, the format for the Rounds is similar but with a number of adaptations. The biggest changes to the standard model are that Rounds are run less regularly in the medical school (the intention is to hold them once per term) and that the attendees are composed uniformly of students rather than a multi-disciplinary group from across the organisations.

The Point of Care Foundation supports organisations with training and mentoring to replicate the Schwartz model, under a licence agreement from the Schwartz Centre for Compassionate Care in the US. 
The student context: Stress, isolation, fragmentation and attrition in health care students and the wider workforce Data from the Health and Safety Executive, workforce survey [13] indicate that levels of stress are particularly high amongst health care staff. The Boorman Report [14] demonstrates clear linkages between staff health and wellbeing and the levels and quality of both patient care and patient satisfaction. The report sets out the case for change and the benefits that will accrue to staff and NHS organisations from effective investment in staff health and well-being. It argues that improving staff health and well-being is not only the right thing for NHS Trusts to do as exemplary employers, but that investment in such services can bring financial and performance benefits. Similarly findings from recent public enquiries looking into hospital malpractice have highlighted the importance of building staff engagement and valuing and supporting staff (Keogh 2013 [15], Francis 2013 [16], Rose 2015 [17]).

If the problem of stress and burnout is to be tackled at the roots, we suggest that effective processes to support staff must be introduced early in training. High attrition rates amongst students in the healthcare professions indicate that stress is felt from the onset of studies [18]. There is significant variation in the recorded rate of attrition between medical schools and nursing establishments, in nursing, the most recent estimates report an overall rate of $24.79 \%$ in the UK, costing an estimated $£ 57$ million annually [19]. In medical students' levels are lower; with a range of studies reporting widely varying rates of between $6-14 \%$ [20]. The loss of students from pre-registration courses, not only has implications on the general nursing shortage within the NHS, but is an unnecessary waste of staff time and resources, and has a potential negative impact upon the individual [21].

There is increasing attention paid to the reasons for attrition both amongst nurses and medical students. Attrition rates are linked to a combination of factors [18, 22]:

- Personal reasons including family issues

- Financial difficulties

- Academic issues

- How well student expectations match provision

- Individual ability to cope when provision doesn't match expectations (resilience)

- Levels of support provided by the academic institution and clinical environment in fostering a sense of belonging

- Stress

Whilst some of the above, including 'family issues' and finances, may be outside the immediate control of the educational environment - others such as disillusionment and stress are issues around which colleges may be able to offer support.

A review of newly qualified nurses [22] illustrates how the gap between theory and practice remains wide and how stressful the transition can be, moving from students to qualified nurses. An article in the Guardian [23] quotes a newly qualified nurse:

"I understand now that you have to be extremely strong emotionally and physically to be a nurse, although we had practical lessons to prepare us for our placements, many of the students, including myself, did not know what to expect from working in a hospital."

An insightful blog from Eric Keller [24], an American medical student, entitled "What is professionalism and wellness in medical education?" suggests how frightening the professional ideal can be when presented to a young student, stressed by new often brutal work environments and multiple work and social demands. Keller stresses the importance of being able to share uncertainties and vulnerabilities that arise:

"Last August I sat surrounded by 163 other ambitious, new medical students on our introduction to the profession' week. Anxiety was high with undertones of self-doubt mixed with lofty goals. Another distinguished figure had taken the floor to introduce us to the concept of medical professionalism: commitments to patient-centred care, intellectual honesty, social responsibility and advocacy. The long list of medical virtues we were to develop, cherish, and exemplify in our next four years and throughout our careers. The moral bar seemed set for a saint, and I began to question whether I belonged among my peers..... I continue to struggle to understand how to uphold the altruistic virtues this field professes while attending to my own well-being."

Keller captures powerfully some of the early dilemmas that health professionals face when entering the career and the weight of responsibility contingent on living up to the high ideals set. The popular press picks up on the tension, often depicting those working in health either as heroes, selflessly promoting and nurturing the health of the nation or, alternatively, as incompetent, psychotic and heartless villains. Dichotomous portrayals of our health care professionals, from the angelic Florence Nightingale on the one hand to the murderous Harold Shipman on the other, abound in the popular press. These images set up the often problematic nature of the relationship that has to be forged between doctors/ nurses/allied health professionals and the general public. 
There is an unease posed by the uncertainty of knowing whether or not to celebrate success or to control, regulate and condemn apparent failure. Keller recognised the complex and often frightening tangle of expectations into which students are thrown.

An interesting finding of the 2014 study of professionalism, by the Health Professions Council, [25] was the crucial role that organisations play in supporting their staff to provide an environment in which professionalism can flourish. Indeed, the aforementioned blog by Keller goes on to describe the value and support he's drawn from a monthly discussion based group - an integral part of the curriculum at his medical school, where they meet to explore 'professionalism and mental well-being'. Keller talks about the physical and emotional mountain that was his first year of studies and the importance of recognizing that he was not alone with his struggles. Sharing monthly blog posts and discussing some of the social and emotional issues which arise during the course of studies proved enormously helpful to Keller

"The path to a career in medicine can be a lonely one, full of vulnerability and self-doubt. These monthly meetings are not only explorations of professionalism but reminders that there are others struggling with us, both at our level and throughout their careers....The medical profession I saw initially seemed invulnerable, but it took time and discussion to appreciate the insecurities and struggles many medical providers share." [24]

\section{Introduction of Rounds to University College of London Medical School (UCLMS)}

Schwartz Rounds have been introduced at UCLMS to expose medical students to an intervention completely different in tone and feel from their normal pattern of lectures and clinical practice - and importantly one that is not marked or examined. The Round is provided purely as space for thinking and reflecting on the social and emotional side of caring for people - there is no problem solving nor is there a list of 'action points' that emerge from the discussion.

"Rounds are a place where people who don't usually talk about the heart of the work are willing to share their vulnerability, to question themselves. Rounds are an opportunity for dialogue that doesn't happen anywhere else in the hospital." Round participant, Point of Care Foundation data

The intention is that the Rounds will help to support students in developing patient-centred communication skills, building an appreciation of the importance of teamwork, and providing a unique space to share emotions and express vulnerability. If students benefit from Rounds in the same way as NHS staff the hope is that medical students will be more supported to work sensitively within a diverse population, thus improving empathy, resilience and compassion for patients, peers and colleagues.

\section{Feedback from students attending Schwartz Rounds at UCLMS}

The first pilot Rounds for year 5 and 6 students were held on teaching days in 2014/15 when all students were on campus for mandatory classes. Attendance was voluntary and a combined total of 438 attended two Rounds. In both cases a multi-professional panel presented stories which had impacted on them emotionally as professionals and following these presentations the discussion was opened up to the floor. At the end of the Rounds students were asked for feedback - both quantitative responding to a number of standard questions on handheld electronic monitors (year 5) and paper forms (year 6). Qualitative free text comments were left on post it notes and a focus group was held with attendees 10 days after the first Round. Results from the pilot [3, 26] show that $80 \%(292 / 365)$ of students said they would attend a future SCR and $64 \%(235 / 366)$ thought that SCR should be integrated into the medical school curriculum. Similarly, $81 \%$ of students either agreed or strongly agreed that the presentation of cases were helpful and gave them insight into how others feel/think about caring for patients. With regard to compassion fatigue, $69 \%(165 / 240)$ of Year 5 students reported being worried about compassion fatigue or burnout, compared with $87 \%(108 / 124)$ of Year 6 students $(p<0.001)$.

The focus group was carried out with a group of year 5 students, 10 days after attending the Round. The discussion was recorded, transcribed and the material subjected to thematic analysis. Although the sample was small $(n=7)$ themes emerge from the analysis of the focus group and free text responses which are consistent with previously hypothesised mechanisms taking place in the Rounds [27], these include:

\section{A welcome opportunity to learn and reflect that isn't graded}

There was a strong feeling in the group that the Round filled a gap in the curriculum. Importantly it was an opportunity that was neither marked nor graded, which provided a completely different insight into everyday studies and practice:

"I felt a deep sense of humility. For all the advances that we have made in medical science, the human touch is still very important." (focus group participant UCLMS) 
"I think Schwartz Rounds are a better way to get people to reflect than the writing tasks that we are made to do through the year - those tasks are just an obligation. You spend an hour the night before competing them before the deadline." (focus group participant UCLMS)

"Yes - this actually encourages people to be reflective. I spoke to loads of people after who were saying - I had this story and then that story. Whether or not they spoke then, they talk about it after. It's really helpful for medics who live together to be able to talk things through over the year - to look at things that were similar and really hard like learning to cope with it." (focus group participant UCLMS)

\section{Creating a culture of openness}

Participants welcomed the introduction to a more open, honest and transparent way of communicating.

"One of the main things that came up with the people that I live with is that there's a lot of concerns about mental health of medical professionals and how they cope with it. Whether it be depression, alcoholism, suicide rate. We're all in a very highly pressurised career and I think that the issues that start to affect you don't start when you are an F1 - they start when you're in medical school. And having a way to cope with those emotions - to be able to say why that patient upset you - to have a safe place to do this, rather than go home and have a glass of wine kind of attitude is so positive. If you can incorporate it into your educational life it becomes so much more natural." (focus group participant UCLMS)

\section{Normalising emotions}

Students recognised the value of being given license/permission to express vulnerability - sometimes relating it to experiences they had during their clinical practice the previous year.

"It was nice to have had the opportunity to hear the stories and experiences of the panel. It made me realise that the emotions and feelings I have encountered over the past year are also experienced by top consultants, doctors and nurses. Thank you for the opportunity." (focus group participant UCLMS)

“.... Similar experiences happen to everyone but you'd never know it without groups like this" (focus group participant UCLMS)

\section{Promoting connectedness}

A number of students mentioned that the Round had helped them to connect more with other students and staff. It also promoted a better understanding of different professional roles and areas of expertise.

\section{Role modelling}

Providing an opportunity for more senior staff to model specific behaviours was appreciated.

"... that surgeon is so high up I would normally be intimidated by him. I'm a medical student and don't want to \{be seen to\} say anything stupid - but his presentation made him so much more approachable. So if I now had him \{for a teacher\} and you find a situation upsetting - you would be much more likely to say something - or be more open with him. Not be so scared to say something that might seem a bit... it's good bridging. (focus group participant UCLMS)

"The most poignant case for me was the junior doctor talking about confronting death. The important thing for him wasn't what he said - it was just the message that he gave to us about the importance of 'getting to know death'. It wasn't' like instructions on what to do when you see someone who is dying - 'make sure you do this, this and this'. Everything in medicine is so formulaic - 'when you see this, do this' - but the Round wasn't prescriptive like that - it was 'make sure you find out your own way of dealing with different situations" (focus group participant UCLMS)

\section{Building resilience to protect students from disengagement/compassion fatigue}

Students were familiar with the concept of compassion fatigue and burnout and were committed to finding ways to protect themselves from it. There was disagreement in the group regarding the manner in which compassion fatigue sets in - with some of the group feeling that doctors were more likely to grow more disengaged in response to the pressures of the job, whilst others felt that it was only once you reached the top of your profession and you no longer had to prove your worth, that you could show more care and compassion towards your patients.

"I think it's definitely something that you are aware of as you go through medical school. I don't know if you would call it compassion fatigue or burnout or distancing or cutting yourself off but I think that in certain specialties in particular you see a distancing ... That's partly why I thought that it is good to talk about it. When it's your mum or dad that's different to when you see Mr. or Mrs. so and so in a clinic. For 
you to be a Dr. you have to cut off a bit - but you don't want it to be so much that you don't care. I think that it's something that we learn the more experienced we become. Maybe it should be talked about earlier on - you don't want to arrive at your first SHO job to discover that you just don't care anymore. You want to still care." (focus group participant UCLMS)

\section{What are the benefits to the organisation of investing in Rounds?}

Setting up Schwartz Rounds demands a level of organisational investment, both in terms of the training and support contract payable to POCF and the internal costs of staff time, refreshments, possible venue hire etc. In a large NHS trust where Rounds run once per month the commitment in terms of staff time amounts to at least one day/month for the facilitator and administrator and half a day from the clinical lead and steering group. In educational environments this will vary depending on the numbers of Rounds run. Whilst running Rounds isn't cost neutral the long term benefits linking better staff engagement to decreased sickness absence and improved output is increasingly well articulated. The Boorman Report [13] demonstrates clear linkages between staff health and wellbeing and the levels and quality of both patient care and patient satisfaction. The work sets out the case for change and the benefits that will accrue to staff and NHS organisations from effective investment in staff health and well-being. It argues that improving staff health and well-being is not only the right thing for NHS Trusts to do as exemplary employers, but that investment in such services can bring financial and performance benefits.

Also pertinent here is Jill Maben's research on a cohort of nursing students. Maben found that whilst nurses go into the profession with strong ideals, the system has a tendency to shake these ideals out of them, reducing both their resilience and their ability to treat patients with compassion [12]. Maben found that high ideals and values, can become abandoned and crushed, with nurses reporting some degree of burn out within two years of qualification:

"Across all staff groups, the demands of caring work mean that cynicism can develop and staff can become less empathetic and more distant from their patients. It is therefore critical to protect staff from the ravages of caring work. Everyone needs support and renewal." [12]

In a separate [28] study Maben demonstrates the importance of staff wellbeing on patient well-being, showing that levels of stress and engagement in staff affect the way they communicate and care for patients. Results showed that in most cases where patient experience is good, staff wellbeing is good and vice versa. Findings suggest that individual staff wellbeing is best seen as an antecedent rather than a consequence of patient care performance. These finding suggest it is important to invest in and support individual staff wellbeing at work in order to enable staff to better deliver high quality patient care.

The causal relationship between the emotional work and stress of caring for patients and rates of depression in health care workers is not known. But depression and high stress affect the performance of staff in a variety of ways [29] through the resulting difficulties in memory, decision-making, concentration and irritability, and the links to the abuse of alcohol and other drugs.

Burnout is similar to stress, consisting of the three key areas of a lowered sense of personal effectiveness, emotional exhaustion, and depersonalisation (developing negative perceptions about patients) [30]. Psychodynamic literature discusses depersonalisation as the area that is most likely to limit compassion, or at worst can produce cruelty to patients.

Stress and mental health issues are the most common cause of sick-leave in high-pressure workplaces [31] which in turn increases spends on agency staff; the latest figures (Work Foundation blog [32]) suggest that the NHS spent $£ 1.8$ billion on agency and contract staff in 2014, twice what had been planned.

\section{Conclusion: going forward}

Early results from the pilot at UCLMS suggest that the Rounds are generally well received by those who choose to attend - though further research is needed to explore a number of logistical and practical issues including:

- Where do Rounds best sit within the curriculum?

- Should attendance at Rounds be voluntary or mandatory?

- How best to encourage a multi professional perspective

- How to bring about meaningful participation from students in the discussion when group size is so big.

Liverpool University are currently piloting some work funded by Health Education North West where they are planning to bring together multi-professional groups of students. Initially, the Rounds will be based in the medical school but once established there, the invitation to attend the Rounds will go out to a student audience crossing different professional groups, including nurses, psychologists, midwives and other allied health professional groups. Interest to introduce Rounds is also being shown by a number of nursing colleges. 
One important aspect of the work deserving further exploration is the issue of encouraging meaningful participation from students despite large audience size. Feedback from UCL suggested that the large size of the group was, for some, a significant deterrent in feeling able to contribute to the discussion. A number of possible alternative scenarios may be worth testing. Given the time and resources needed to set up and prepare the panel for the Schwartz Round the most cost effective solution may be for the Round to take place in front of the whole year group - but then to break off into smaller groups (say 8-10 students) for reflective discussion. If the time slot was extended from one hour to an hour and a half, the first part of the discussion could include the complete year group, to establish themes and seek feedback from the presenting panel, before breaking into smaller groups for the last half hour. Smaller groups could be student or staff moderated depending on availability.

It is our hope that Rounds in student establishments will become a routine part of a wider array of structural mechanisms made available to offer support to students from across professional disciplines. Evidence demonstrates that offering interventions such as Schwartz Rounds not only supports students to be more compassionate, both to themselves and others, but also helps model more open, transparent methods of communication and fosters better team work. Whilst setting up Schwartz Rounds is not cost neutral, the potential impact in terms of: reduction in student stress; more open, compassionate conversations; improved engagement and reduced attrition, may have significant short and long term gains and warrants further research.

\section{Competing interests}

Dr. Jocelyn Cornwell and Rhiannon Barker both work for the Point of Care Foundation responsible for supporting the implementation of Schwartz Rounds across the UK. Dr Faye Gishen works at Marie Curie Hospice Hampstead and UCLMS where Schwartz Rounds are run.

\section{Authors' contributions}

RB produced the first draft of the paper and amended it following feedback from JC and FG. FG, with support from the Point of Care Foundation, initiated and facilitated the Rounds at UCLMS, based on which much of the thinking behind this paper has emerged. All authors saw and approved the final version of the paper.

\section{Author details}

'Head of Business Development, Point of Care Foundation, 99 Gray's Inn Road, London W1X 8TY, UK. ${ }^{2}$ Chief Executive, Point of Care Foundation, 99 Gray's Inn Road, London W1X 8TY, UK. ${ }^{3}$ Consultant in Palliative Medicine and Honorary Senior Lecturer in Medicine, Royal Free Hospital, Pond Street, London NW3 2QG, UK

Received: 28 December 2015 Accepted: 7 March 2016 Published online: 18 March 2016

\section{References}

1. Doctors in society: Medical professionalism in a changing world. Technical supplement to a report of a Working Party of the Royal College of Physicians of London. December 2005. https://cdn.shopify.com/s/files/1/ 0924/4392/files/docs_in_socs_tech_navigable.pdf?2801907981964551469 Accessed 13 December 2015.

2. Training future doctors how does medical education need to adapt? The Guardian Higher Education Network http://www.theguardian.com/highereducation-network/2015/apr/13/training-future-doctors-how-does-medicaleducation-need-to-adapt Accessed 2 December 2015.

3. Gishen F, Whitman S, Gill D, Barker R, Walker S. Incorporating Schwartz Centre Rounds in the undergraduate curriculum: what do medical students think? BMC Medical Education. 2016. (submitted)

4. GMC 'Promoting excellence: standards for medical education and training' Published July 2015.http://www.gmc-uk.org/education/standards.asp. Accessed 3/8/2016

5. Lown B, Manning C. The Schwartz Center Rounds: Evaluation of an interdisciplinary approach to enhancing patient-centered communication, teamwork and provider support. Academic Medicine. 2010;85(6):1073-81.

6. The Schwartz Centre. https://www.theschwartzcenter.org/about-us/storymission Accessed 13th December 2016

7. NIHR HS\&DR Full Application: Detailed Project Description Full title of project: A Longitudinal National Evaluation of Schwartz Centre Rounds ${ }^{\circledast}$ : an intervention to enhance compassion in relationships between staff and patients through providing support for staff and promoting their wellbeing http://www.nets.nihr.ac.uk/_data/assets/pdf_file/0004/129631/PRO-13-0749.pdf Accessed 2/25/2016

8. White M \& Epston D. Narrative means to therapeutic ends. New York: WW Norton \& Company; 1990

9. Rogers C, Farson R. Active Listening. Chicago: University of Chicago Industrial Relations Center. 1957

10. Goodrich J. Supporting hospital staff to provide compassionate care: Do Schwartz Center Rounds work in English hospitals? JRSM. 2012;105(3):117-22.

11. Menzies-Lyth I. Containing Anxiety in Institutions. London: Free Association Press; 1988.

12. Maben J. Support staff to support patients. The Health service journal. 2013; 123(6371):20. https://www.researchgate.net/publication/259565144_ Support_staff_to_support_patients. Accessed August 2015 p.2. 12. HSE Health and safety in human health and social care in Great Britain. 2014 http://www.hse.gov.uk/statistics/industry/healthservices/health.pdf.

13. COI for the Department of Health NHS Health and Well Being; the Boorman Report Final report; November 2009 http://webarchive.nationalarchives.gov. uk/20130107105354/http://www.dh.gov.uk/prod_consum_dh/groups/dh_ digitalassets/documents/digitalasset/dh_108907.pdf. Accessed 3/8/2016

14. NHS Choices. "Review into the quality of care and treatment provided by 14 hospital trusts in England: overview report." Sir Bruce Keogh KBE. 16 July 2013. www.nhs.uk/NHSEngland/bruce-keogh/Documents/outcomes/keoghreview-final-report.pdf.Accessed 3/8/2016

15. Francis R. Report of the Mid Staffordshire NHS foundation trust public inquiry: executive summary 2013. (Vol. 947). The Stationery Office.www.ipem.ac.uk Portals/0/Documents/Consultations/Francis\%20Report\%20Feb\%2020 13\%20Executive\%20Summary. Accessed 3/8/2016

16. Department of Health. Better leadership for tomorrow: NHS leadership review. Lord Rose. 2015 https://www.gov.uk/government/uploads/system/ uploads/attachment_data/file/445738/Lord_Rose_NHS_Report_acc.pdf

17. Orton S. 'Re-thinking attrition in student nurses' Journal of Health and Social Care Improvement. February issue. 2011.http://www.wlv.ac.uk/media/wlv/pdf/ Rethinking-Attrition-in-student-nurses-Sophie-Orton.pdf. Accessed 3/8/2016

18. Nursing Standard. High nursing attrition rates cost UK 57 million (pounds sterling) a Year. Nursing Standard. 2006;20(23):6.

19. Maher B, Hynes H, Sweeney C, Kashan A, et al. Medical School AttritionBeyond the Statistics: A Ten Year Retrospective Study. BMC Medical Education. 2013;13:13

20. Pryjmachuk S, Easton K, Littlewood A. Nurse education: factors associated with attrition. Journal of Advanced Nursing. 2009;65(1):149-60.

21. Hamshire C, Spearing R, Wibberley C. Innovative Thinking; Student and newly qualified staff attrition scoping review. Final report. Manchester Metropolitan University. September 2014

22. Draper J, Sparrow S, Gallagher D. Crossing the threshold: students' experiences of the transition from student to staff nurse. University of Cambridge. In: Nurse Education Today Conference, 8-10 Sep 2009, http:// oro.open.ac.uk/26544/. Accessed 13 December 2015

23. Shepherd J. Keeping Students on Course. 2009. http://www.theguardian. com/education/2009/nov/24/nurses-degree-diploma-carer-clinician Accessed 13 December 2015 
24. Keller EJ. What is professionalism and wellness in medical education? Education. 2014. http://www.kevinmd.com/blog/2014/08/professionalismwellness-medical-education.html Accessed 2 December 2015

25. HCPC. Professionalism in healthcare professionals. Research report. Health Care and Professions Council. 2014.

26. Gishen F, Gill D, Barker R, Walker S. 'Should Schwartz Centre Rounds be incorporated into medical school curriculum? A qualitative and quantitative exploration of student's views' Poster presented at UCLPartners Education Conference Educating for Patient-Centred Care. October 2015

27. Barker R, Flanagan E. Schwartz Rounds: Social and Emotional Support for Every Staff Member. In: Bostock L. Interprofessional Staff Supervision in Adult Health and Social Care Services. Volume 1. Pavilion Annual 2016

28. Maben J, Adams M, Peccei R, Robert G. Poppets and parcels: the links between staff experience of work and acutely ill older people's experience of hospital care. International Journal of Older People Nursing: Special Issue: Acute Care. 2012;7:2, 83-94.

29. Firth-Cozens J. Interventions to improve physicians' well-being and patient care. Soc Sci Med. 2001;52:215-22.

30. Schaufeln W. 'Burnout'. In: Firth-Cozens J, Payne RL, editors. Stress in Health Professionals. Chichester: Wiley; 1999. p. 17-32.

31. CBI Fit for Purpose. Absence and workplace health survey. 2013.

32. The high costs of temporary agency staff in the NHS. Barjorek Z. June 2015. http://www.theworkfoundation.com/blog/2497/The-high-costs-oftemporary-agency-staff-in-the-NHS Accessed 7 December 2015.

\section{Submit your next manuscript to BioMed Central} and we will help you at every step:

- We accept pre-submission inquiries

- Our selector tool helps you to find the most relevant journal

- We provide round the clock customer support

- Convenient online submission

- Thorough peer review

- Inclusion in PubMed and all major indexing services

- Maximum visibility for your research

Submit your manuscript at www.biomedcentral.com/submit 